\title{
Analysis of Bidirectional Converter with Coupled Inductor for Electric Drive Application
}

\author{
Slavomir Kascak \\ Faculty of Electrical Engineering, Dept. of Mechatronics and Electronics, University of Zilina, 01026 Univerzitna 1, Slovakia
}

\begin{abstract}
This paper deals with analysis of the two-phase interleaved DC-DC converter for bidirectional current flow between the input sources and three-phase inverter for the electric drive. The bidirectional non-isolated topologies of DCDC converter are also mentioned. In the paper is analyzed the current ripple reduction by using the coupled or uncoupled form of the inductors in the converter. The mathematical equations are supplemented by the simulation results.
\end{abstract}

Keywords-coupled inductor; bidirectional converter

\section{INTRODUCTION}

Nowadays, in electric vehicle application, the nonisolated buck-boost converters are used for the maintaining the constant voltage in DC-bus [1]- [4].

For the higher power application there are more possibilities how to perform higher power density in regard to efficiency of the converter. First choice is to utilize of the paralleling of the power switches, shown in Fig. 1. This converter includes only one inductor and parallel connected two half-bridge leg. This is done for reasons of obtaining higher current ratings, thermal improvements, and sometimes for redundancy. If losses are not equally shared, the thermal differences between the devices will lead to other problems and the possible failure of the transistors Therefore, the thermal coefficient of the collector-emitter voltage $\mathrm{V}_{\mathrm{CE}}(\mathrm{SAT})$ is an important parameter when paralleling IGBTs. It must be a positive to allow current sharing. On the other hand the higher positive thermal coefficient is the higher losses arise because at high temperature the $\mathrm{V}_{\mathrm{CE}}(\mathrm{SAT})$ is increased.

The second option how to share the current is to use the interleaved topology, Fig. 2. The same problem as in the previous topology with current sharing is eliminated because the current is divided between two paralleled buckboost converters. The advantageous of this connection is in improved power density. A comparison between multiphase buck and multichannel boost converter can be summarized in the following features: the power density improvement, same as in the buck, the interleaved effect reduces the total input and output current ripple, so this means the smaller input filter for the buck converter and also smaller output filter (bulk capacitor) for the boost converter [5].

In the high current application there are used the interleaved topologies even with the coupled inductors on the core. The advantageous of the coupled inductor is in lowered current ripple direct on the inductors not only in the output or input current of the bidirectional converters. The interleaved buck converter with coupled inductance are used in VRM application and interleaved boost converter in PFC application due to smaller inductor current ripple and improved the steady state efficiency [6], [7].

Therefore, in this paper the advantageous features of the coupled inductor will be analyzed on bidirectional buck boost inverter for higher power application in electric drive.

\section{CURRENT RipPle REDUCTION EFFECT OF COUPLED INDUCTOR}

In this section, the effect of a coupled inductor on ripple current reduction is discussed in greater detail. As we know the interleaved topology connection does not maintain lower inductor current ripple only in the case the inductors are coupled. This section is divided into two parts. Firstly, an impact of the coupled inductor on buck topology is investigated, the non-coupled buck is compared to coupled buck converter and ripple reduction is shown in a graph. Secondly, the same comparison is discussed for coupled boost converter.

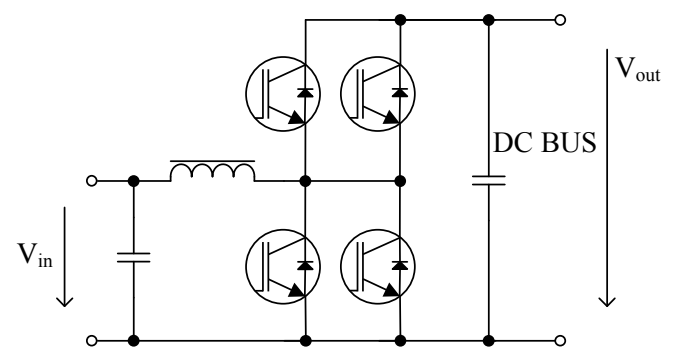

FIGURE I. BIDIRECTIONAL DC-DC CONVERTER FOR HIGHER POWERAPPLICATON

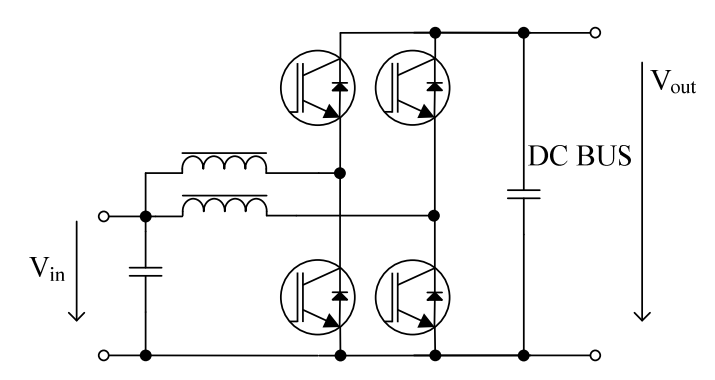

FIGURE II. INTERLEAVED BIDIRECTIONAL DC-DC CONVERTER FOR HIGHER POWERAPPLICATON 
In the two-phase interleaved converter the four different operating modes occur. The first interval begins when the switch S1H and S2L are closed and appropriate equation can be obtained, (1) and (2). From the equation is seen that the current ripple is the same in both phases and this refer to all intervals of operation. The output current ripple is described in (3). It is obvious that the output current ripple is lowered. An inductor current ripple reduction in one interval of operation are expressed as followed:

$$
\begin{gathered}
\Delta i_{L 1}=\frac{V_{\text {in }}}{L}(1-D) D T_{S}=\frac{V_{\text {out }}}{L}(1-D) T_{S} \\
\Delta i_{L 2}=-\frac{V_{\text {in }}}{L}(1-D) D T_{S}=-\frac{V_{\text {out }}}{L}(1-D) T_{S}
\end{gathered}
$$

Then, by summing (1) and (2) the equation for output current ripple reduction is

$$
\Delta i_{\text {out }}=\Delta i_{L 1}+\Delta i_{L 2}=\frac{V_{\text {out }}}{L}(1-2 D) T_{S}
$$

The same equation is obtainable also for boost converter with the difference that the output current is replaced with the input current $i_{\text {in }}$.

\section{A. Two-Phase Coupled Buck Converter}

A simplified schematic for a coupled buck converter is depicted in Fig. 3.

According Kirchhoff's law the following equation for two-phase coupled buck converter can be written (4)-(9):

$$
\begin{gathered}
I_{\text {out }}=I_{1}+I_{2} \\
V_{L K 1}=V_{\text {in }}-V_{\text {out }}-V_{M} \\
V_{L K 2}=V_{M}-V_{\text {out }} \\
I_{M}=I_{1}-I_{2}
\end{gathered}
$$

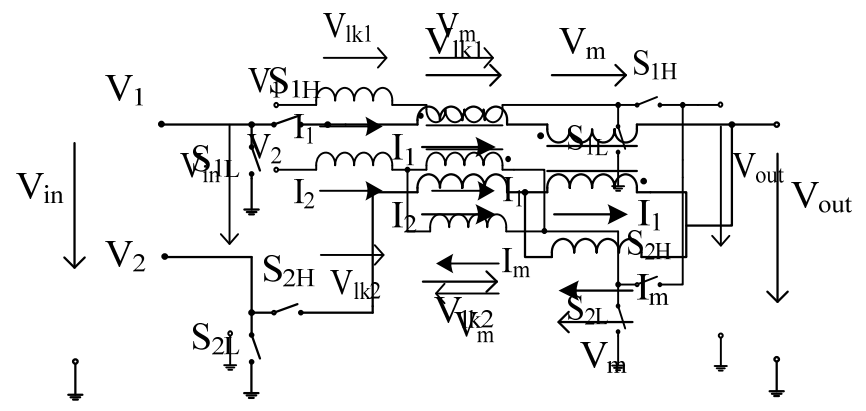

FIGURE III. A SIMPLIFIED SCHEMATIC OF TWO-PHASE COUPLED BUCK CONVERTER

$$
\begin{gathered}
V_{M}=L_{M} \frac{d i_{M}}{d t}=L_{M} \frac{d i_{M}}{d t}\left(\frac{d i_{1}}{d t}-\frac{d i_{2}}{d t}\right) \\
V_{M}=\frac{L_{M}}{L_{k}+2 L_{M}} V_{\text {in }}
\end{gathered}
$$

Using the mathematical operation the equation as in the non-coupled case obtain. The following equations refer to the first and third interval of operation [4].

$$
\Delta i_{L 1}==\frac{V_{\text {out }}}{L_{k}}\left(1-D-\frac{L_{M}}{L_{k}+2 L_{M}}\right) T_{S}
$$

$$
\Delta i_{L 2}==\frac{V_{\text {out }}}{L_{k}}\left(\frac{L_{M}}{L_{k}+2 L_{M}}-D\right) T_{S}
$$

$$
\Delta i_{\text {out }}=\Delta i_{L 1}+\Delta i_{L 2}=\frac{V_{\text {out }}}{L_{k}}(1-2 D) T_{S}
$$

For the second and fourth interval of operation the ripple is same for both phase currents.

$$
\Delta i_{L 1}=\Delta i_{L 2}=-\frac{V_{\text {out }}}{L_{k}}(0.5-D) T_{S}
$$

$$
\Delta i_{\text {out }}=\Delta i_{L 1}+\Delta i_{L 2}=-\frac{V_{\text {out }}}{L_{k}}(1-2 D) T_{S},
$$

From (3), (12) and (14) is evident that output current ripple is the same (except the negative sign in (14)) under the condition that non-coupled inductance $\mathrm{L}$ is equaled to leakage inductance $\mathrm{L}_{\mathrm{k}}$.

\section{B. Two-Phase Coupled Boost Converter}

A simplified schematic for a coupled buck converter is depicted in Fig. 4.

FIGURE IV. A SIMPLIFIED SCHEMATIC OF TWO-PHASE COUPLED BUCK CONVERTER

The following equations for the boost converter refered to the first and third interval of operation are:

$$
\begin{gathered}
V_{\text {in }}=V_{L K 1}+V_{M} \\
V_{\text {in }}-V_{\text {out }}=V_{L K 2}-V_{M}
\end{gathered}
$$


The output current and also the magnetizing current are same as for the buck converter, (4) and (7). Using the same procedure the equations for the first and third interval of operation are as follows:

$$
\begin{gathered}
\Delta i_{L 1}==\frac{V_{\text {out }}}{L_{k}}\left(1-D-\frac{L_{M}}{L_{k}+2 L_{M}}\right) D T_{S} \\
\Delta i_{L 2}==\frac{V_{\text {out }}}{L_{k}}\left(\frac{L_{M}}{L_{k}+2 L_{M}}-D\right) D T_{S}
\end{gathered}
$$

For the second and fourth interval of operation the ripple is same for both phase currents.

$$
\Delta i_{L 1}=\Delta i_{L 2}=-\frac{V_{\text {out }}}{L_{k}}(0.5-D) D T_{S}
$$

The total output current for the coupled boost converter is written in (21) and is the same as in the non-coupled one.

$$
\Delta i_{\text {out }}=\Delta i_{L 1}+\Delta i_{L 2}=\frac{V_{\text {out }}}{L_{k}}(1-2 D) D T_{S}
$$

\section{Comparison of coupled and non-coupled converter}

The comparison of the coupled and non/coupled converter for the buck and also the boost converter is derived in (21) and plotted Fig. 5. As shown in Fig. 5, a smaller current ripple can be achieved with strong coupling coefficient.

$$
\frac{\Delta i_{\text {Lcoupled }}}{\Delta i_{\text {Lnoncoupled }}}=\frac{L}{L_{k}} \frac{1-\frac{D k}{1-D}}{1+k}
$$

For the volume reduction of the coupled inductor the relationships in (22) should be taken into consideration, Fig. 6.

$$
\frac{\Delta I_{\text {Lcoupled }}}{\Delta I_{\text {Lnoncoupled }}}=\frac{I_{D C}+\frac{\Delta i_{\text {Lcoupled }}}{2}}{I_{D C}+\frac{\Delta i_{\text {Lnoncoupled }}}{2}}=\sqrt{\frac{1-k}{1+k}}
$$

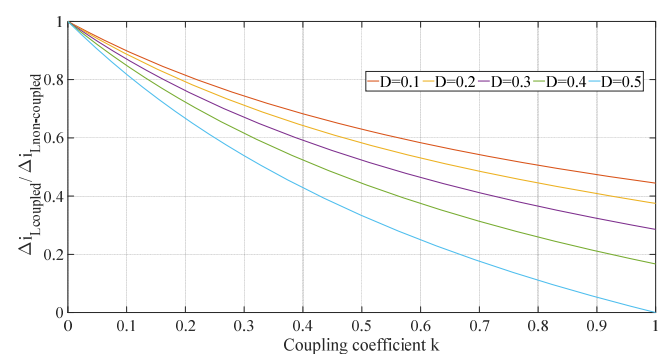

FIGURE IV. INDUCTOR CURRENT RIPPLE OF COUPLED INDUCTOR NORMALIZED TO NON-COUPLED CASE
The curve plotted in Fig. 6 shows that how much smaller must be the peak current of coupled inductor to uncoupled one.

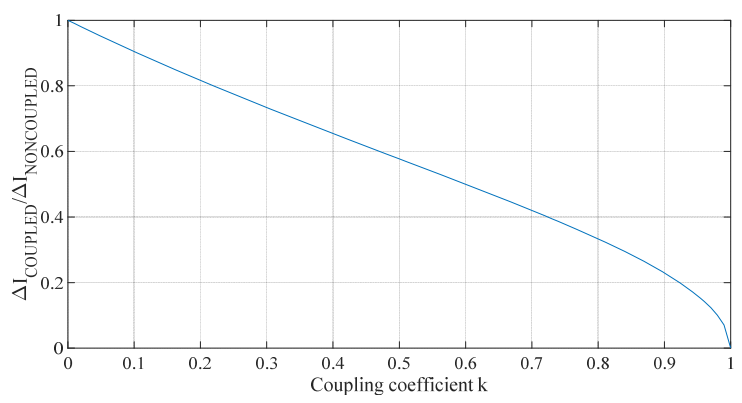

FIGURE V. INDUCTOR CURRENT RIPPLE OF COUPLED INDUCTOR NORMALIZED TO NON-COUPLED CASE

\section{Simulation Results}

As mentioned in section II, the inductor current ripple is strongly dependent on the coupling coefficient $\mathrm{k}$ of the coupled inductor. In order to have the maximum inductor current ripple reduction, the coupled inductor should have high $\mathrm{k}$ and also have enough leakage inductance to reduce output current ripple, simultaneously. From the simulation results in Fig. 7 until Fig. 12 is shown that with increasing of the coupling coefficient the ripple of inductor current is decreasing with maintaining the leakage inductance equals to non-coupled inductance.

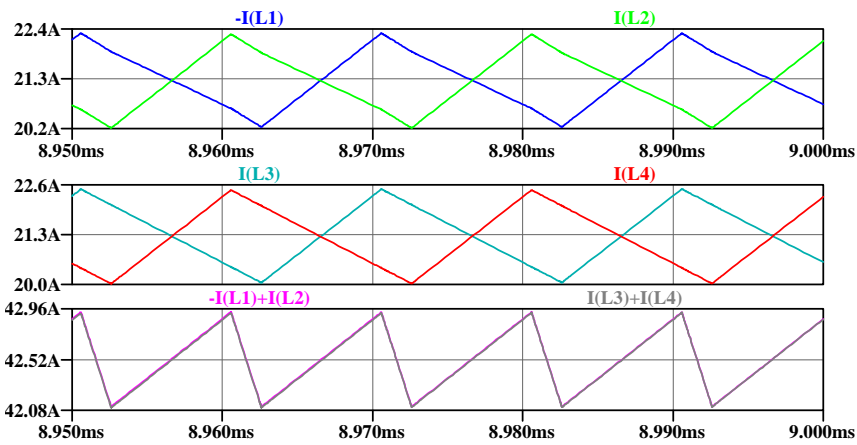

FIGURE VI. COUPLED BOOST UNDER CONDITION $(\mathrm{k}=0.1, \mathrm{D}=0.4$, $\mathrm{Vin}=160 \mathrm{~V} \mathrm{R}=10 \Omega$ )

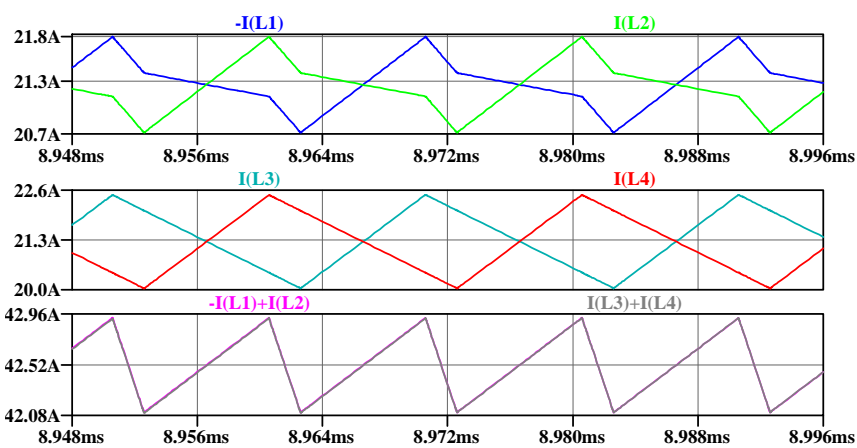

FIGURE VII. COUPLED BOOST UNDER CONDITION $(\mathrm{k}=0.5, \mathrm{D}=0.4$, $\mathrm{Vin}=160 \mathrm{~V} \mathrm{R}=10 \Omega$ ) 


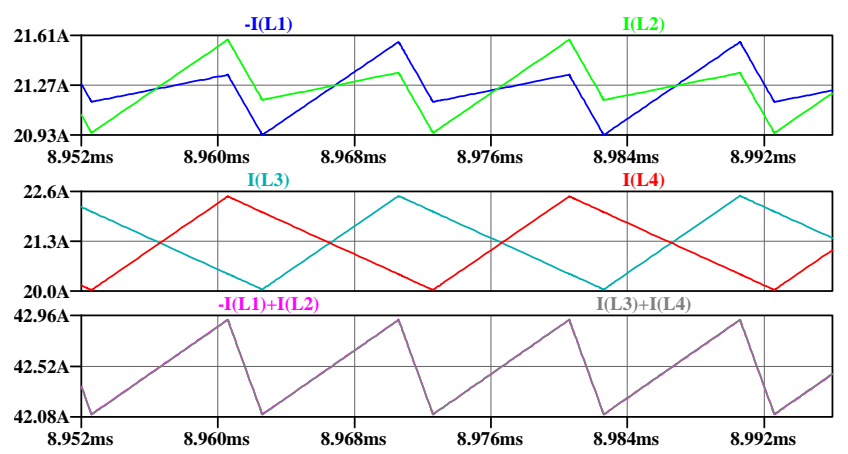

FIGURE VIII. COUPLED BOOST UNDER CONDITION $(\mathrm{k}=0.8, \mathrm{D}=0.4$, $\mathrm{Vin}=160 \mathrm{~V} \mathrm{R}=10 \Omega$ )

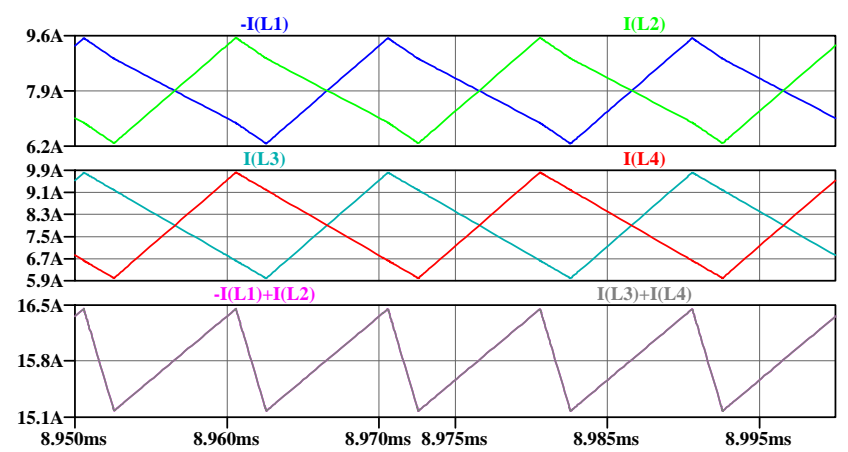

FIGURE IX. COUPLED BUCK UNDER CONDITION $(\mathrm{k}=0.1, \mathrm{D}=0.4$, $\operatorname{Vin}=160 \mathrm{~V} \mathrm{R}=10 \Omega$ )

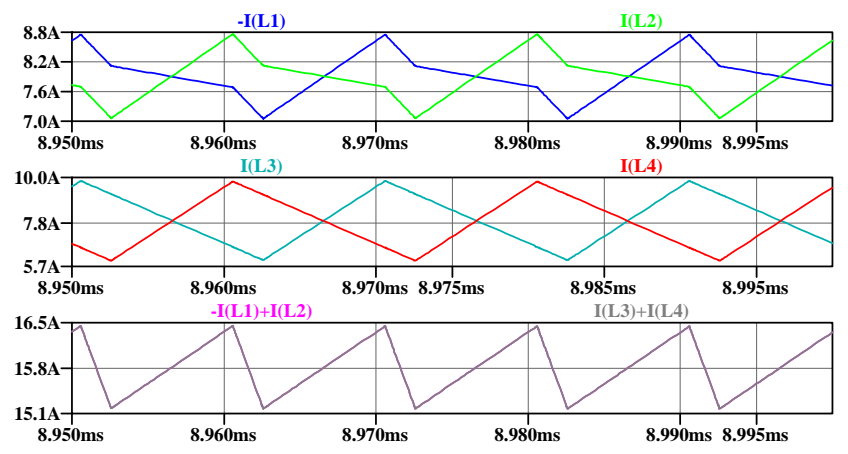

FIGURE X. COUPLED BUCK UNDER CONDITION $(\mathrm{k}=0.5, \mathrm{D}=0.4$, Vin $=160 \mathrm{~V} \mathrm{R}=10 \Omega$ )

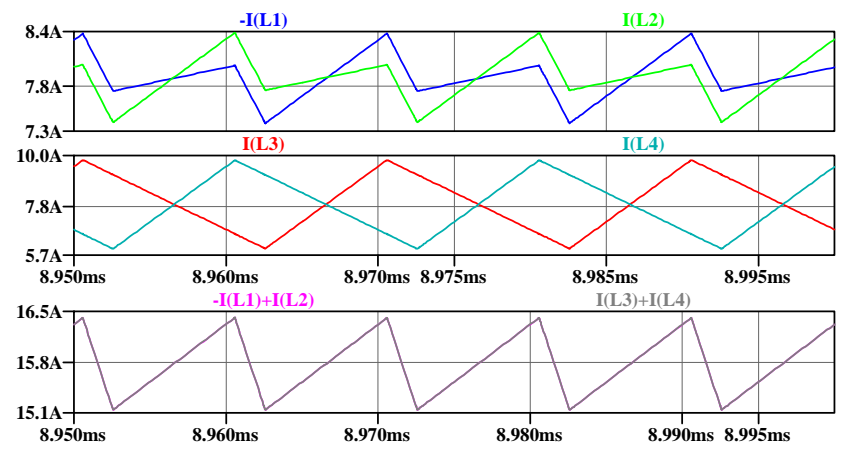

FIGURE XI. COUPLED BUCK UNDER CONDITION $(\mathrm{k}=0.8, \mathrm{D}=0.4$, $\mathrm{Vin}=160 \mathrm{~V} \mathrm{R}=10 \Omega$ )

\section{CONCLUSION}

In order to reduce inductor current ripple as well as input/output current ripple respectively according which topology is used the two inductors should be coupled on one core. It is more preferable to use coupled inductor topology in high current application due to better utilization of the coupled effect. To preserve the required ripples on the inductor and on the input/output respectively, the coupling coefficient must agree. For the input/output current respectively, the leakage inductance is very important and must be equal to the non-coupled inductance to maintain criterion. Therefore, for the high value of coupling coefficient the mutual inductance increases and the total value of the inductance in coupled connection is higher than in non-coupled connection. Therefore, the volume of the inductor depends on inductor's energy. If the current ripple reduction in coupled converter is high enough to maintain the total energy is lower than the energy in the non-coupled converter, then utilization of the coupled inductor is advantageous.

\section{ACKNOWLEDGMENT}

This paper is supported by the following projects: APVV-15-0571.

\section{REFERENCES}

[1] J. Cao; A. Emadi, "A New Battery/UltraCapacitor Hybrid Energy Storage System for Electric, Hybrid, and Plug-In Hybrid Electric Vehicles," IEEE Transactions on Power Electronics, , vol.27, no.1, pp.122-132, Jan. 2012.

[2] R.M. Schupbach, J.C. Balda, "35 kW Ultracapacitor Unit for Power Management of Hybrid Electric Vehicles: Bi/directional DC-DC Converter Design," 35th Annual IEEE Power Electronics Specialists Conference, Vol.3, pp. 2157 - 2163, 2014.

[3] B. Kozacek, M. Frivaldsky, M.Piri, "Forward converter with active clamp and synchronous rectifier," International journal on energy conversion, Vol. 2, no. 6, pp. 179-183, 2014.

[4] P. Spanik, M. Frivaldsky, P. Drgona, V. Jaros, " 11th IEEE international conference ELEKTRO 2016," pp. 231-237, May 2016.

[5] J.P.Lee, H. Cha, D. Shin, K.J. Lee, “Analysis and Design of Coupled Inductors forTwo-Phase Interleaved DC-DC Converters," Journal of Power Electronics, Vol. 13, No. 3, pp. 339-348, May 2013.

[6] J. Gallagher, "Coupled Inductors Improve Multiphase Buck Efficiency," Power Electronics Technology, pp. 36-42, January 2006.

[7] K. Kroics, U. Sirmelis, V. Brazis "Design of coupled inductor for interleaved boost converter," Przeglad Elektrotechniczny,Vol. 90, Nr. $12 / 2014$. 